\title{
EXTENSÃO UNIVERSITÁRIA COMO ESPAÇO DE CONSTRUÇÃO DE INSTRUMENTOS DE EDUCAÇÃO POPULAR EM ACAMPAMENTOS URBANOS*
}

\author{
Eblin Farage \\ Francine Helfreich \\ Camila Barros Moraes \\ Maria Caroline da Silva Souza
}

\section{Introdução}

A proposta deste texto consiste em analisar a experiência desenvolvida pela extensão universitária, organizada pelo Núcleo de Estudos e Pesquisas sobre Favelas e Espaços Populares (NEPFE) da Universidade Federal Fluminense (UFF), que tem como foco do trabalho o debate sobre questão urbana, direito à cidade, formação profissional e movimentos sociais urbanos, pautado no tripé ensino-pesquisaextensão. O objetivo da experiência socializada era contribuir para a formação profissional de discentes de Serviço Social a partir da realização de ações articuladas com o Movimento dos Trabalhadores Sem Teto (MTST), movimento social de luta pelo direito à moradia, assim como fortalecer o papel social da Universidade Pública. A relação necessária entre o Serviço Social e os movimentos sociais, é referendada nos princípios da profissão a partir das escolhas políticas realizadas no pós 1979 que são determinantes para a construção do projeto ético político da profissão. Assim, o presente capítulo pretende socializar a experiência e alguns dos instrumentos construídos a partir da perspectiva da educação popular.

O debate sobre os movimentos sociais que marcou os anos 1980 e início dos anos 1990, se enfraqueceu no âmbito da profissão com o advento do neoliberalismo, com a expansão de ações das organizações não governamentais (ONG) e com as alterações nas requisições profissionais oriundas das transformações do mundo do trabalho. Já na segunda década dos anos 2000, diante do recrudescimento do conservadorismo e da ascensão da extrema direita no Brasil, experiências vinculadas à educação popular, articulação com os movimentos sociais e a organização coletiva ganharam nova ênfase, diante do desafio de fazer frente a um projeto societário cada vez mais excludente que intensifica a pauperização da classe trabalhadora.

Nessa conjuntura de crise estrutural do capitalismo, de fragmentação das organizações coletivas da classe trabalhadora e de retrocessos nos direitos sociais conquistados - em especial a partir da Constituição Federal de 1988 (CF/88) -, o Serviço Social é instado a intensificar o debate sobre a relação entre a profissão e os movimentos sociais. Nesse sentido, é imprescindível recuperar a contribuição da educação popular no processo de formação da consciência crítica dos trabalhadores e a função social que a Universidade pública pode ter a partir de ações extensionistas.

"DOI - 10.29388/978-65-86678-92-5-0-F.65-81 
Mediante as experiências junto ao MTST que adentra nas favelas do Rio de Janeiro especialmente entre 2014 e 2018, foi possível uma rápida, mas intensa aproximação com determinados territórios urbanos tão apartados pelo poder público de políticas públicas de qualidade. Bairros periféricos que, compõem hoje um mosaico urbano marcado pelo desenvolvimento territorial desigual e combinado.

Motivado pelas questões citadas, nossa proposta consiste em fazer o debate do trabalho profissional nas favelas, a partir da experiência extensionista realizada nas 03 ocupações construídas pelo MTST. Estes que, ao (re)inaugurarem ${ }^{1}$ suas ações no estado do RJ, construíram de pronto uma aproximação com a Universidade através do NEPFE requisitando ações profissionais junto às famílias que se inseriram no movimento.

Para tanto, o texto versará sobre dois eixos centrais: primeiro localizaremos o debate sobre o território e seus sujeitos, a relação extensão universitária e movimentos sociais, a partir do espaço das favelas, em um país de capitalismo dependente. Assim situando a experiência do MTST nos municípios de São Gonçalo e Niterói no RJ. No segundo eixo apresentaremos a experiência do projeto de extensão elaborado e desenvolvido pelo Serviço Social, as expressões da questão social encontradas evidenciando a organização do processo de formação profissional. Pontuando as rotinas e atividades realizadas; a elaboração e utilização dos instrumentos técnico-operativos (entrevistas, visitas domiciliares) e ainda as principais sínteses construídas que expressam os desafios, dilemas e os limites da experiência ancoradas nas determinações teórico- metodológica, ético-politica e técnico-operativa da profissão.

Por fim, partindo de uma assertiva de Minayo, que diz que "nada pode ser intelectualmente um problema se não tiver sido, em primeiro lugar, um problema da vida prática" (2005, p. 17), este artigo se dispõe a analisar os experimentos realizados, tendo como base a pesquisa bibliográfica que subsidiará a partir da teoria a análise das questões postas pela realidade social.

Venha! Entre na experiência de um trabalho social em territórios periféricos e com movimentos sociais, deixe-se tomar pelos seus dilemas, se encante com as suas riquezas, se inspire nas suas resistências!

\section{De que território estamos falando?}

As experiências de extensão universitária desenvolvidas pelo NEPFE se materializaram em diferentes espaços. Inicialmente nas comunidades do Complexo de Favelas da Maré no Rio de Janeiro, posteriormente em favelas de São Gonçalo e Niterói. Houve ainda, experiência extensionista na escola pública. Todas permeadas pela tríade formação - papel social da universidade pública - articulação social, que tão bem a extensão universitária consegue agregar.

Assim, compreendendo como afirma Chizzotti (2008, p.79), que "o objeto não é um dado inerte e neutro; está possuído de significados e relações que sujeitos concretos criam em suas ações", um dos passos iniciais dos projetos de extensão foi

\footnotetext{
${ }^{1}$ Reinaugurar por que o MTST já havia realizado trabalho no Rio de Janeiro na década de 1990, ficando afastado de ações no estado por cerca de 10 anos e retornando na segunda década dos anos 2000.
} 
proporcionar, junto aos discentes e docentes envolvidos, um (re)conhecimento dos sujeitos residentes nos territórios. Assim como de suas demandas, histórias coletivas e algumas vezes também individuais, sua inserção social e as expressões da questão social por eles vivenciadas.

Para Silva e Barbosa (2005), as favelas são vistas como espaço da ausência, da precariedade e da falta de recursos. Nesse sentido, passam a ser consideradas uma "cidade" à parte da cidade formal. Um espaço que se constitui com regras próprias, no qual o Estado não pode intervir. Considerada pelo senso comum como espaço da prostituição, da vagabundagem, da malandragem e da desordem, seus moradores acabam sendo colocados em uma posição de não-sujeitos e não-cidadãos ${ }^{2}$. Essa imagem construída histórica e culturalmente sobre as favelas cariocas, contribui para a reprodução de estigmas e estereótipos que acabam por afastar seus moradores das oportunidades, serviços e direitos que a cidade oferece aos seus habitantes.

Assim, chegamos a algumas das perguntas orientadoras do projeto de extensão. Quem são os moradores da periferia urbana? Como e onde vivem? Do que precisam? Essas perguntas, para além das indagações sociais e profissionais que já tínhamos, se encontrou com a análise de que o Serviço Social, como profissão, pode ter uma relação mais estreita com os movimentos sociais, compreendendo esses como sujeitos coletivos capazes de impulsionar mudanças sociais que impactam a vida cotidiana dos trabalhadores e trabalhadoras pauperizados da periferia.

Considerando que o território é ao mesmo tempo produto e produtor das relações sociais, expressando contradições, disputas, tensões e resistências, o levantamento dos dados sobre o território e a cidade foi o ponto inicial para o desenvolvimento das ações extensionistas. Nesse processo, o (re)conhecimento dos municípios de São Gonçalo e de Niterói, com sua história, contradições socioeconômicas foi o ponto de partida.

Trata-se de dois municípios limítrofes, que compõem a região metropolitana do Rio de Janeiro, e que guardam inúmeras desigualdades como expressão da questão social. São Gonçalo, segunda maior cidade do estado do Rio de Janeiro com cerca de 1.091.737 moradores, inferior apenas à capital. Seu Índice de Desenvolvimento Humano Municipal (IDHM), segundo os dados do Instituto Brasileiro de Geografia e Estatística (IBGE), melhorou bastante nos últimos 20 anos, passando de 0,550 em 1991 para 0,739 em 2010. Toda sua população se divide em uma área predominantemente urbana e periferizada e também em uma ainda extensa área rural, que ocupa uma área territorial de 248,160 Km.

No que tange às condições de vida, a precarização se agudiza, abrigando uma das maiores favelas planas da América Latina, o Jardim Catarina. Um bairro popular e populoso que gradativamente foi se favelizando e sendo submetido ao poder do tráfico de drogas no varejo. Uma das expressões das precárias condições de vida é o índice de mortalidade infantil, que apesar de considerado baixo pela classificação do Sistema Único de Saúde (SUS), se comparada ao município vizinho, Niterói, é alta. Em São Gonçalo a taxa chega a 12,75 óbitos por mil nascidos vivos, enquanto em Niterói a taxa é de 9,63 segundo os dados do IBGE/2017.

${ }^{2}$ Entendendo como Cidadão o ser da cidade, da polis, que pode usufruir de todos os espaços, serviços e direitos. 
Um município pauperizado, que apesar de oficialmente ter uma população entre 06 e 14 anos em sua totalidade na escola, chegando a 96,7\% (IBGE,2019), é marcada por uma baixa qualidade do ensino público fundamental. No âmbito da educação superior, abriga um importante campus da Universidade do Estado do Rio de Janeiro (UERJ).

Entre os muitos aspectos da realidade cotidiana que explicitam as desigualdades em ambas as cidades, merece destaque, o fato de Niterói, com quase a metade dos moradores de São Gonçalo, com cerca de 515.317 mil pessoas, possuir mais que o dobro de receitas realizadas, se compararmos apenas o ano de 2017. Enquanto São Gonçalo teve em 2017 R\$ 1.064.524,12788, Niterói teve R\$ 2.767.516,39545, ou seja, de forma per capita, um morador de Niterói "recebeu" quase 6 vezes mais investimento do que um morador de São Gonçalo.

Ao analisar o Produto Interno Bruto (PIB) per capita, que apesar de não expressar a igualdade na distribuição, expressa, em parte, a produção de riqueza circulante de uma cidade, a desigualdade também é evidente. Primeiro porque explicita a grande concentração de renda, típica de um país de capitalismo tardio e dependente, que a cada ano concentra mais riqueza e segundo porque agudiza a desigualdade entre os municípios vizinhos. Em São Gonçalo o PIB per capita é de R\$ 16.408,34 já em Niterói de $\mathrm{R} \$ 55.049,66$.

Mesmo com as profundas diferenças sociais, econômicas, culturais e políticas, entre os municípios, estes possuem, em comum, um contingente de trabalhadores e trabalhadoras pauperizados, explorados, subempregados, "patrões de si mesmos" em trabalhos autônomos, ou seja, largados a sua própria sorte, nos termos de Antunes (2018), buscando o privilégio da servidão. Essa população, residente em favelas e periferias de ambas as cidades, vivem a degradação humana com a precariedade das suas condições de moradia.

Assim, a luta pela moradia, entremeada com a luta pelo direito à cidade, marca parcelas da população que ousam viver a experiência de organização coletiva em um movimento social de luta por moradia, o MTST. É nesses territórios, que novos espaços de sociabilidade vão sendo gestados, a partir da organização coletiva e da vivência da organização política que reivindica direitos. Esses experimentos, proporcionam para quem os vivencia, seja como integrante da luta, seja como apoiadores e/ou técnicos à disposição da luta por direitos sociais, um aprendizado marcante para a formação e ampliação da consciência crítica e social. A desnaturalização das desigualdades, a explicitação das injustiças e da precária política pública gestada pelos poderes públicos, são alvo tanto das reivindicações dos trabalhadores organizados coletivamente, como dos profissionais ou futuros profissionais envolvidos no processo reivindicatório.

Mas como elemento fundante do processo de reconhecimento do território de atuação, um dos passos iniciais, nas experiências desenvolvidas, era reconhecer os sujeitos sociais envolvidos. Por um lado, o MTST, e por outro, os trabalhadores e trabalhadoras que se organizavam para a ocupação de terrenos e para a luta em defesa da moradia e do direito à cidade.

Assim, o primeiro movimento, além de conhecer o território físico, foi conhecer o MTST, um movimento de luta pelo direito à moradia com perspectiva 
anticapitalista. O MTST havia ganho grande expressão nacional no início da segunda década dos anos 2000 a partir da projeção e da visibilidade que as ocupações em São Paulo tiveram em todo o país. Nesse processo, forjou-se uma de suas principais lideranças, Guilherme Boulos ${ }^{3}$, jovem de classe média que decidiu dedicar a vida à militância na luta pelo direito à moradia. As lutas em São Paulo, maior cidade do país, impulsionaram a organização do movimento em seis estados, a saber: RJ, PE, RR, ES, GO, SP além do Distrito Federal.

A ação do movimento concentra-se nas ocupações de terras urbanas, pressionando diretamente os proprietários e o Estado, denunciando o problema social da moradia e construindo um processo de organização autônoma dos trabalhadores. Uma forma de ação que é estratégica para o MTST são os bloqueios de rodovias e avenidas, por meio da ação direta, coletiva e organizada o Movimento. Busca ressignificar, em ato, o terreno, criando um episódio no combate à especulação imobiliária e sua cadeia de agenciamentos, assim como denunciando a dinâmica de segregação urbana na formação social brasileira.

O movimento realizou, nesse seu segundo momento no RJ, três ocupações, a primeira na cidade de São Gonçalo em 2014 e as outras na cidade de Niterói, uma em 2015 e outra em 2018. Vale destacar que o processo de mobilização do MTST não se encerra com o final das ocupações, mas se mantém com outras mobilizações. 0 ato da ocupação constitui apenas a primeira fase de mobilização, responsável pelo maior tensionamento com o poder público. O projeto de extensão, esteve imbricado com esses processos tanto durante as ocupações como nas fases posteriores, constituindo-se como um importante espaço de aprendizagem sócio-profissional para os discentes de Serviço Social.

Com esse intuito o projeto de extensão se encontrou com as cerca de 446 famílias em São Gonçalo e com 304 em Niterói. As famílias de São Gonçalo tinham sua trajetória marcada pela imigração - em especial do nordeste - e pela baixa escolaridade. As famílias de Niterói, muitas tinham em comum, serem sobreviventes do desabamento do Morro do Bumba, ocorrido em 2010. Ainda em comum, tinham a absoluta insuficiente das ações do Estado para a garantia de direitos, contando com uma ação de necropolítica, como afirma Mbembe (2018), escolhendo os que podem morrer e deixando-os à sua própria sorte.

Estando as famílias à sua própria sorte, o trabalho realizado pelo MTST passou a ser um diferencial em suas vidas. Um sopro de esperança, advindo da luta, passou a compor a história de vida marcada por injustiças, retirada de direitos, segregação e subalternização daqueles sujeitos. Os cantos, entoados nas assembleias de base dos acampamentos, refletem a força emanada dos trabalhadores reunidos e organizados coletivamente, como a música que dizia "fazenda velha, cumieira arriou/ Levanta negro, cativeiro acabou/Se negro soubesse o talento que ele tem/ Não aturava desaforo de ninguém".

É assim, na busca do (re)conhecimento dos sujeitos históricos que ali se dispunham a lutar que a nossa equipe do Serviço Social integrou-se à luta, disposta a subsidiar tecnicamente a mediação a acesso a direitos. Contribuindo na organização

\footnotetext{
${ }^{3}$ Guilherme Boulos se candidatou a prefeito de São Paulo pelo PSOL em 2020, mas em 2018 já havia sido candidato a presidente da república pelo mesmo partido.
} 
da luta pelo direito a moradia, iniciando nossa intervenção a partir do processo de levantamento do perfil social das famílias acampadas.

Em São Gonçalo, na ocupação Zumbi dos Palmares, foram aplicados 446 questionários e em Niterói, na ocupação 06 de Abril, 304. Sendo um questionário por família, o levantamento social caracterizou cerca de 1526 e 1338 pessoas, respectivamente vinculadas aos questionários respondidos nos dois municípios.

Entre os respondentes dos questionários nos dois municípios, se evidenciou que em São Gonçalo 83\% se autodeclararam não brancos e em Niterói 80,3\%. A Renda familiar de $54 \%$ das famílias de São Gonçalo é de até um salário mínimo e em Niterói $41,7 \%$. A junção racial com a pauperização familiar é entendida como uma das marcas estruturantes da segregação social e espacial no Brasil. Marcas de um país escravocrata que tem na particularidade de sua constituição social o racismo estruturante.

No que tange à inserção no mundo do trabalho, os dados reforçam a tríade pobreza- questão racial - local de moradia. Em São Gonçalo $46 \%$ trabalham longe da residência e dependem de transporte público. $49 \%$ dos membros destas famílias são trabalhadores informais, sendo apenas $17 \%$ os que possuem vínculo formal com carteira de trabalho, e $28 \%$ desempregados, não realizando nenhum tipo de trabalho informal.

Dos trabalhadores da ocupação Zumbi dos Palmares, 53\% não possuíam o número de identificação social (NIS), e com isso estavam inviabilizados de acessar todo e qualquer tipo de programa da assistência social, uma vez que desde 2003 foi instituído o Cadastro Único (Cadúnico), como forma de acesso em todo o país. No que se refere à educação, 39,5\% declara ter parado de estudar para trabalhar, e $21,1 \%$ para cuidar dos filhos. Assim, mais uma tríade se estabelece, a da baixa escolaridade-baixa renda- difícil acesso aos direitos sociais.

Entre os pobres, pretos, de baixa escolaridade e com trabalho precário, as mulheres correspondem a $79 \%$ das respondentes e também consideradas responsáveis pelo lar. Assim, mais uma vez se evidencia, que no Brasil, a classe trabalhadora mais pauperizada, tem raça e gênero, o que nos coloca o desafio de debater de forma interseccional classe-raça-gênero.

$\mathrm{Na}$ ocupação 06 de abril, 3,81\% dos membros das famílias cadastradas, não eram alfabetizados e $22,05 \%$ tinham apenas o ensino fundamental incompleto. Das famílias dos respondentes, $23 \%$ possuem mais de 06 pessoas no mesmo domicílio, em sua maioria em casas alugadas ou cedidas, em especial após o desastre do Bumba.

Entre o formal e o informal, entre aprender a lutar e sonhar e acima de tudo resistir e persistir na luta pela vida e pela moradia, a equipe do projeto de extensão aprendeu e reaprendeu. Partimos do (re)conhecimento do território e de seus sujeitos, inspirados pela teoria, por categorias centrais que nos impulsionavam a ir ao encontro dos sujeitos, a buscar os movimentos sociais como parceiros privilegiados da Universidade pública, gratuita e socialmente referenciada, como será explicitado a seguir. 


\section{Para iluminar a reflexão}

Partimos do pressuposto que a extensão universitária é parte constitutiva do tripé (ensino, pesquisa e extensão) enquanto eixo conceitual que sustenta as análises críticas sobre o modelo de educação superior em curso, elaborado a partir do entendimento do que é a Universidade Pública. Aqui se reivindica uma Universidade vinculada à perspectiva de que a educação é um direito social, e que portanto, deve ser pública, laica, gratuita, antipatriarcal, antiracista, anticapacitista, antisexista, antilgbtfobica e socialmente referenciada.

A extensão universitária é entendida como "[...] um conjunto amplo de atividades que perfazem processos de cunho educativo, cultural e científico, indissociados da pesquisa e do ensino, que apontam para a relação entre a universidade e o conjunto da sociedade." (Pnex, 2001, p.03). Já no Plano Nacional de Extensão Universitária, elaborado pelo Fórum de Pró-Reitores de Extensão das Universidades Públicas Brasileiras e pela Secretaria de Educação Superior do Ministério da Educação e do Desporto, publicado em 2001, é expresso o "[...] compromisso da universidade com a transformação da sociedade brasileira em direção à justiça, à solidariedade e à democracia." (Pnex, 2001, p.03), valores estes que são ofuscados através de ações e projetos que, quase sempre passam longe das pautas dos movimentos sociais e dos interesses da sociedade em geral. Compartilhamos o entendimento de que, as ações de extensão vinculadas às atividades gratuitas, de interesse geral e articuladas a movimentos sociais deveria ser o foco de uma Universidade socialmente referenciada, já que através da extensão é possível desenvolver ações contra hegemônicas.

Como um dos pilares que sustentam a concepção de universidade baseada na troca de saberes e na convivência, a extensão é uma forma de realizar, institucionalmente, a partilha, a troca e o compartilhamento de saberes entre Universidade (academia) e sociedade como via de mão dupla, extrapolando os seus muros. Objetivando capturar o movimento das relações sociais constituídas no cotidiano da vida na favela, as ações desenvolvidas buscavam a apropriação da realidade, como momento necessário à reflexão teórica. Tendo como base o método histórico-dialético como forma de apropriação da realidade e partindo das categorias de totalidade ${ }^{4}$ contradição, processualidade e mediação.

No que tange à formação profissional de assistentes sociais, atualmente a extensão universitária vem ocupando importantes debates na categoria profissional seja devido às normativas do Conselho Nacional de Educação (CNE), seja pelas próprias exigências da atual conjuntura. Em dezembro de 2018 foi publicada uma resolução do CNE que afirma que "a extensão precisa compor no mínimo, 10\% (dez por cento) do total da carga horária curricular estudantil dos cursos de graduação, as quais deverão fazer parte da matriz curricular dos cursos". Isto posto, há uma

\footnotetext{
${ }^{4}$ Segundo Lukács, "Não é o predomínio de motivos econômicos na explicação da história que distingue de maneira decisiva o marxismo da ciência burguesa, mas o ponto de vista da totalidade. A categoria da totalidade, o domínio universal e determinante do todo sobre as partes constitui a essência do método que Marx recebeu de Hegel e transformou de maneira original no fundamento de uma ciência inteiramente nova" (Lukács, 2003, p.105).
} 
tendência de que o lugar da extensão seja redefinido, não apenas para formação de assistentes sociais, como nos demais bacharelados. Com isso, talvez essa seja a oportunidade de apostar nas experiências de Educação Popular - tão lateralizada nos últimos 20 anos nos componentes curriculares dos cursos de Serviço Social -, mas que em alguma medida se apresentam nas pautas e reivindicações dos movimentos sociais, partidos progressistas e grupos políticos.

A compreensão que permeou a realização de tal experiência é a de que a articulação com os movimentos sociais se caracteriza como elemento central para a formação profissional. Nesse sentido, a busca por caminhos que extrapolam a institucionalidade estatal torna-se essencial, uma vez que, as respostas do Estado às expressões da questão social e as lutas dos trabalhadores se constituem cada vez mais de um caráter fragmentado, conservador e punitivo.

Assim, encontramos no Projeto Ético-Político do Serviço Social, solidificado a partir da década de 1990, arcabouço para tais ações. De maneira explícita esse projeto apresenta-se atrelado ao projeto societário da classe trabalhadora e com compromisso de construção de uma nova ordem. Desse modo, seguindo a direção hegemônica da profissão, anticapitalista, e os princípios descritos em seu Código de Ética Profissional de 1993, quais sejam, a defesa do aprofundamento da democracia, enquanto socialização da participação política e da riqueza socialmente produzida; opção por um projeto profissional vinculado ao processo de construção de uma nova ordem societária, sem dominação, exploração de classe, etnia e gênero; articulação com a luta geral dos/as trabalhadores/as, inspiram essa experiência.

No Brasil a Educação Popular fica conhecida a partir da contribuição de Paulo Freire, ainda na década de 1960, mas que permanece atual. As marcas deixadas na organização de um método de educação de jovens e adultos, que buscava contribuir para a consciência crítica dos trabalhadores, extrapola suas experiências e contagia a extensão universitária junto aos movimentos sociais. Dentre um conjunto de valorosas reflexões, há que se destacar a concepção de mundo que atravessa toda a obra do autor pernambucano, onde sua leitura do mundo é expressa no compromisso com os "esfarrapados do mundo". Para os/as assistentes sociais, a educação popular pode ser uma mediação importante para a apropriação, conhecimento e reconhecimento da realidade do cotidiano daqueles com os quais trabalhamos. Conforme as sínteses de Silveira, cuja concepção compartilhamos, e que iluminou as bases para nossa experiência, a educação popular é entendida como:

1- Como um investimento político que constrói um lugar voltado para o processo de conhecimento da realidade.

2- Como espaço que vai possibilitar o trânsito do senso comum ao bom senso. Lugar de apropriação individual e coletiva, no qual está presente uma dimensão ideológica fundamental: a de compreender a base de estruturação da vida social sob o capitalismo e da conformação possível de alternativas de organização da vida social, sob outras bases.

3- Como espaço das classes trabalhadoras a conformar outro NÓs, antagônico ao hegemônico, este último constituído sob a égide do 
individualismo, da ausência de solidariedade etc. Portanto, espaço no qual possam ser experimentados novos valores, novos pensares, numa dimensão de práxis na qual ativamente se busca a elaboração da realidade a partir de uma perspectiva humanosocial.

4- Finalmente, um espaço no qual os sujeitos possam exercitar o singular exercício de suas próprias sínteses, redefinindo e recriando referências de vida, sentidos novos à sua existência individual e coletiva (Silveira, 2004, p. 122).

Portanto, através da Educação Popular é possível socializar informações, compartilhar saberes, estimular a participação política e em alguma medida construir resistências. E assim contribuir para o processo de formação de consciência que se choque às relações de dominação impostas pelo capitalismo e estruturantes da desigualdade.

Reconhecendo a trajetória da Educação Popular no Brasil e na América Latina, requer pontuar que a mesma se desenvolve em um território, ou em vários territórios, onde os sujeitos que lá vivem, criam suas histórias, se produzem socialmente e também resistem. E ao construir suas resistências, se utilizam de formas de fazer educação produtora e reprodutora de conhecimentos; formas essas que foram ou são extremamente necessárias para suas lutas e existência, como é o caso das produzidas pelos moradores dos territórios através da relação com o MTST.

A produção de autores como Milton Santos que analisa e interpreta as cidades a partir da leitura territorial como expressão do conjunto de relações sociais, condições e acessos produzidos pelo desenvolvimento desigual, entendem tais espaços a partir do significado dos atores que dele se utilizam. Compreendendo que a identidade se relaciona com o pertencimento do sujeito, ou seja, é 'um ato de pertencer àquilo que nos pertence', aquilo que dá sentido na vida cotidiana. Assim, "[...] o território é o fundamento do trabalho, o lugar da residência, das trocas materiais e espirituais e do exercício da vida" (Santos, 2002, p. 10). Ou seja, a produção de políticas públicas - tão reivindicadas pelos movimentos sociais - precisa ter sentido para aqueles que vivem em determinado lugar, o que pressupõe dialogar com os sujeitos em seu cotidiano, com seus valores, hábitos, costumes, enfim, com um modo de ser e agir no mundo de indivíduos e coletivos sociais.

Para Santos, o território é o lugar que desembocam todas as ações, todas as paixões, todos os poderes, todas as forças, todas as fraquezas, isto é, onde a história do homem plenamente se realiza a partir das manifestações da sua existência (Ibid., p.13).

Neste sentido, o território, é construído com referência das relações sociais em que as pessoas estão envoltas, relações estas que são sempre, também, relações de poder. Por isso importante elucidar que o território é algo para além de um espaço geográfico, mas são espaços da fruição da vida, de relações, de trocas, de construção e desconstrução de vínculos, contradições, conflitos, e de múltiplos significados para os sujeitos. Assim, pensar o território e as políticas públicas significa compreender a forma como as expressões da questão social se revelam nos distintos lugares, seja nas favelas, nas comunidades ribeirinhas, indígenas, quilombolas, ou 
seja, significa compreender sem homogeneizar as realidades diversas. Assim, de forma mais abrangente e próxima da concepção teórica que inspira as reflexões, Heasbaert nos ajuda a reafirmar a necessidade de pensar o território de forma atrelada aos sentidos que os mesmos possuem para a vida dos sujeitos

[...] dentro do materialismo histórico e dialético, irá defender uma noção de território que: i) privilegia sua dimensão material, sobretudo no sentido econômico, ii) está historicamente situada e iii) define-se a partir das relações sociais nas quais se encontra inserido, ou seja, tem um sentido claramente relacional (Heasbaert, 2002, p.45).

Portanto, dimensão territorial implica em tratar a cidade, seus territórios e os moradores que neles vivem de forma imbricada, como uma totalidade, já que os mesmos podem ser considerados como o chão da política pública tão - reivindicada pelos movimentos sociais e pelo Serviço Social.

Considerando o território e as reflexões teóricas acumuladas no âmbito da Universidade, foi possível desenvolver a experiência extensionista, a partir de intrínseca relação com o MTST e os trabalhadores e trabalhadoras participantes das ocupações em busca da moradia. Essa experiência, entre as muitas mediações necessárias, foi também tangenciada pela criação e uso de instrumentos técnicooperativos que fizeram dessa prática, uma experiência a ser partilhada.

\section{Adapte, use e reutilize: Um pouco da experiência}

Do tripé ensino, pesquisa e extensão, nasce a experiência do NEPFE e a parceria com o MTST. Eivada de contradições e aprendizados, a extensão como eixo de ligação da Universidade com a sociedade, efetiva a função social da educação pública superior. Assim compreende-se que as ações de extensão, socialmente referenciadas, são uma via de mão-dupla de produção e interlocução de conhecimento, e possuem um significado singular na formação profissional, ao promoverem a articulação entre teoria e realidade social. Conforme aponta Faceira (2013), o processo formativo dos discentes deve ir além da aquisição de conhecimentos técnicos científicos, pois quando estes não são integrados à realidade são esvaziados.

Apesar de a extensão ser uma parte constitutiva e complementar do tripé das Universidades, existe uma dicotomia entre esta e o ensino e a pesquisa, sendo a primeira secundarizada em relação aos outros dois pontos. Compreendemos que em uma conjuntura de contrarreformas, que impactam diretamente as Universidades públicas, estão postos desafios para a materialização de uma formação profissional em todas as dimensões que a Universidade dispõe e que "a extensão reflete as condições da sociedade na qual nos encontramos historicamente, marcada por contradições e permeada por avanços e retrocessos" (Faceira: 2003, p. 7).

Consideramos que a persistência e defesa de um ensino superior que articule o ensino, a pesquisa e a extensão é essencial para uma formação discente que 
promova a aquisição e o desenvolvimento de conhecimentos e habilidades nas diferentes dimensões necessárias ao fazer profissional.

Nessa perspectiva, o projeto que teve início em 2014, tendo como objetivo estimular o debate sobre o direito à cidade, tendo como mediação a luta pela moradia e a organização dos trabalhadores em movimentos sociais, a partir da experiência junto ao MTST nas comunidades de São Gonçalo e Niterói, possibilitou a construção de importantes instrumentos para a prática profissional. Tendo como eixo central das ações o debate sobre a questão urbana com foco no direito a moradia e a todos os demais direitos inerentes à vida na cidade, foi desenvolvido um movimento de aproximação e articulação com as políticas públicas, assim como o desenvolvimento de instrumentos que permitiram o (re)conhecimento dos sujeitos e seu território.

\section{- Organização do trabalho}

O trabalho do Serviço Social junto ao MTST inicialmente foi marcado pela desconfiança, dada as experiências anteriores do movimento com a profissão no estado de PE e SP. Segundo o relato dos dirigentes do movimento as "assistentes sociais só iam lá nos acampamentos para ameaçar tirar as crianças" e "cumprir as ordens da prefeitura e da polícia". Assim, o primeiro ponto foi "conquistar" a confiança e mostrar que a ação do Núcleo não era punitiva, mas sim participativa e de assessoria na mediação da luta por direitos. Assim, após o estabelecimento da relação, mesmo que inicialmente não superada a "desconfiança", deu-se início à ação extensionista quando o movimento, junto com o conjunto de moradores e pessoas ocupou um terreno abandonado há mais de 30 anos no bairro de Santa Luzia, cidade de São Gonçalo.

Os principais pontos de desenvolvimento do trabalho foram: [i] elaboração de questionário social para mapeamento do perfil das famílias; [ii]realização de levantamento das demandas sociais dos acampados da Ocupação Zumbi do Palmares, referentes a documentação, escolarização, moradia, trabalho, saúde, lazer e etc; [iii] desenvolvimento do trabalho de formação com coordenadores de núcleos de base e lideranças; [iv] realização de oficinas a partir de temas específicos e das demandas identificadas junto aos cadastrados no movimento; [v] realização de trabalho de memória do processo de luta construído pelo MTST em São Gonçalo e Niterói; [vi] realização de mapeamento e articulação institucional dos serviços públicos e de organizações não governamentais para encaminhamentos que visaram a garantia de direitos aos trabalhadores da região; [vii] construção de atividades com o objetivo de reforçar a organização comunitária e mobilização dos moradores.

A inserção de docentes, discentes e profissionais do Serviço Social possibilitou a realização do trabalho de cadastro geral dos acampados da "Ocupação Zumbi dos Palmares", assim como a aplicação de 446 questionários extensos de mapeamento das condições de vida das famílias que participaram da ocupação. A experiência de São Gonçalo serviu de referência para a construção dos instrumentos de cadastro e pesquisa na "Ocupação 6 de abril de 2010" em Niterói. A partir do preenchimento dos questionários, a equipe do Serviço Social iniciou o acompanhamento de algumas 
famílias que apresentavam demandas complexas.

- Articulação com entidades da classe e a campanha "Menos ódio, Mais moradia"

Sendo o movimento constituído por trabalhadores urbanos em suas diversas expressões, como operários, trabalhadores informais, subempregados, desempregados, homens e mulheres, crianças, moradores em situação de rua e residentes nas periferias das cidades, o preconceito e a discriminação são imensuráveis. A principal forma de atuação do movimento é através da ocupação de terra e a mobilização da população, via ação direta, utilizando as ocupações de terras urbanas como instrumento para pressionar diretamente o poder público, denunciando o problema da moradia e construindo um processo de organização dos trabalhadores, as reações conservadoras eram inúmeras.

Durante as ocupações o NEPFE desenvolveu um conjunto de ações, como a articulação de uma rede de apoio que envolveu uma diversidade de atores sociais e políticos, como partidos de esquerda, sindicatos, grupos culturais e religiosos. No momento em que o acampamento Zumbi dos Palmares foi alvo de um atentado, essa rede articulada contribuiu para a construção de um ato político-ecumênico em solidariedade ao movimento. A ocupação se manteve mesmo com a tentativa de incêndio e com todas as ameaças das forças repressivas do Estado, e iniciou a campanha "Menos ódio, Mais Moradia" que se nacionalizou, ganhando pouco a pouco visibilidade na mídia e apoio de figuras públicas de todo país.

Além do trabalho realizado decorrente dos atendimentos nas assembleias e nos momentos da aplicação do questionário social, os docentes e discentes contribuíram para a construção de um processo de formação com as lideranças e militantes, bem como com o trabalho de memória de todo o processo de organização do MTST. Para a realização deste trabalho, foi fundamental a participação da equipe do Serviço Social nas assembleias realizadas semanalmente pelo movimento. Nelas, foi possível fortalecer os vínculos entre a população e a equipe do Serviço Social, ainda durante a ocupação, e após a desocupação realizar atendimentos individuais e oficinas sobre acesso a direitos, como o exemplo que segue abaixo.

Tema da Oficina: Cadastro Único

\section{1-Introdução}

Com a participação nas assembleias do Movimento dos Trabalhadores Sem Teto Niterói e São Gonçalo foi perceptível a enorme demanda por informações referente ao acesso a programas do governo, que na atual conjuntura convertem-se em direitos, mas que se conformam limitados, focalizados e precários. Com isso, o Projeto elaborou a proposta da oficina para esclarecer dúvidas sobre o Cadastro Único, enfatizando o NIS e o Programa Bolsa Família, pois são os dois pontos mais visados dentro do Cadastro Único. Além disso apresentará outros benefícios como: isenção em concurso público, PRONATEC, tarifa social de energia elétrica, Programa Minha Casa Minha Vida, aposentadoria para pessoas de baixa renda, telefone popular, entre outros.

2-Público - alvo: População das ocupações do MTST no RJ.

3-Objetivo 


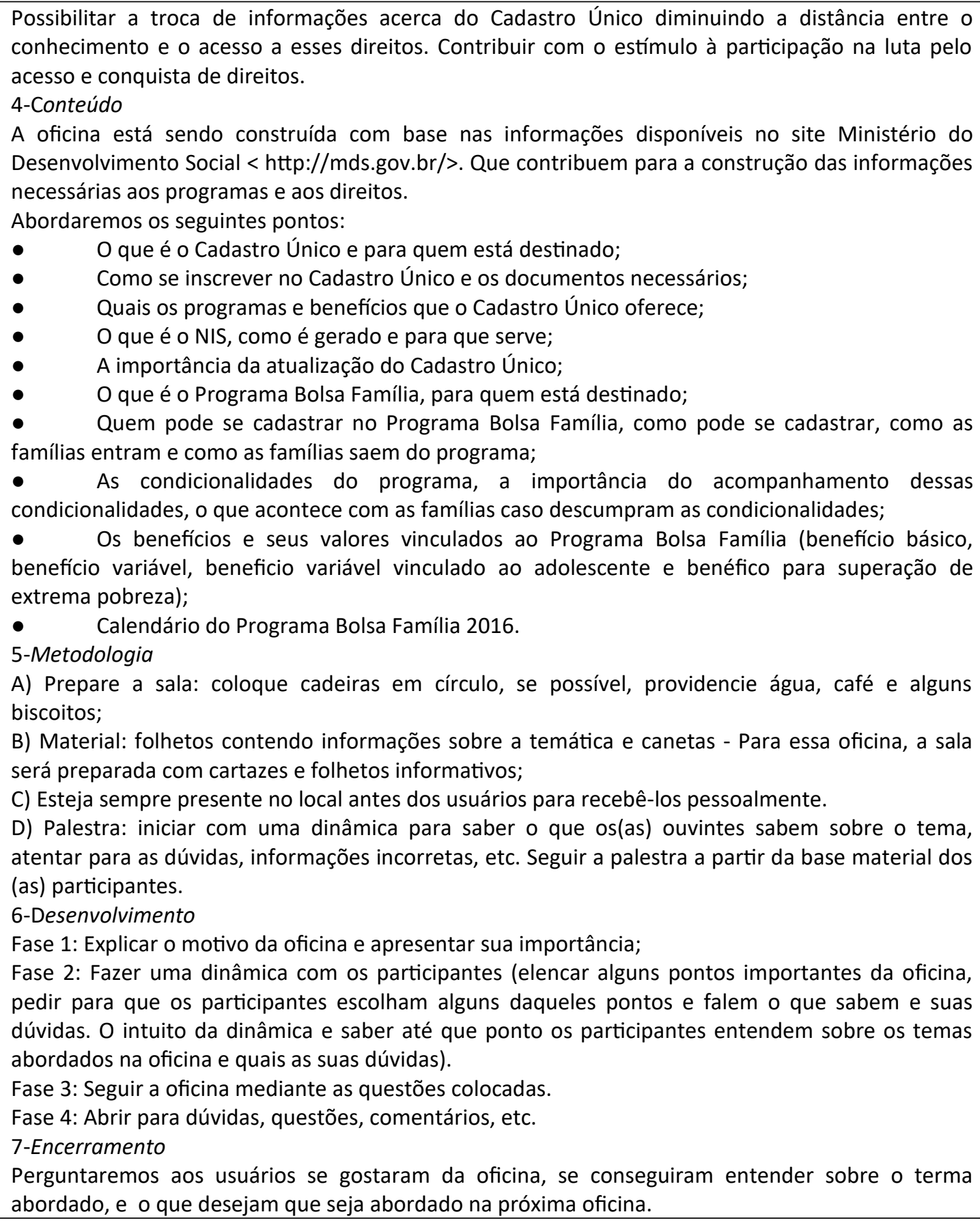

A) Prepare a sala: coloque cadeiras em círculo, se possível, providencie água, café e alguns biscoitos;

B) Material: folhetos contendo informações sobre a temática e canetas - Para essa oficina, a sala será preparada com cartazes e folhetos informativos;

C) Esteja sempre presente no local antes dos usuários para recebê-los pessoalmente.

D) Palestra: iniciar com uma dinâmica para saber o que os(as) ouvintes sabem sobre o tema, atentar para as dúvidas, informações incorretas, etc. Seguir a palestra a partir da base material dos (as) participantes.

6-Desenvolvimento

Fase 1: Explicar o motivo da oficina e apresentar sua importância;

Fase 2: Fazer uma dinâmica com os participantes (elencar alguns pontos importantes da oficina, pedir para que os participantes escolham alguns daqueles pontos e falem o que sabem e suas dúvidas. $O$ intuito da dinâmica e saber até que ponto os participantes entendem sobre os temas abordados na oficina e quais as suas dúvidas).

Fase 3: Seguir a oficina mediante as questões colocadas.

Fase 4: Abrir para dúvidas, questões, comentários, etc.

7-Encerramento

Perguntaremos aos usuários se gostaram da oficina, se conseguiram entender sobre o terma abordado, e o que desejam que seja abordado na próxima oficina.

\section{- Trabalho no território}

Depois que o MTST se retirou do terreno ocupado em São Gonçalo, após o anúncio do acordo com a Prefeitura e com o Governo Federal que garantia a construção de 1000 unidades habitacionais pelo Programa Minha Casa Minha Vida Entidades, os integrantes mantiveram a organização comunitária com os trabalhadores participantes da ocupação que se baseava em três núcleos correspondentes aos locais de origem das famílias acampadas, Jardim Catarina, Santa 
Luzia e Cano-Furado. A equipe do Serviço Social, realizou plantões semanais, durante o ano de 2015, nos respectivos núcleos para aplicações de questionários sociais e acompanhamento das demandas sociais das famílias, assim como participou de todas as assembleias organizadas pelo movimento. As assembleias se constituíram como espaços de mobilização e formação política dos moradores ao longo do processo de luta pela conquista da moradia.

Nas assembleias, a equipe do Serviço Social pôde identificar as dificuldades que as famílias possuíam para compreender e acessar direitos. Dos mais simples, como a emissão e retirada de documentos pessoais e a inserção no Cadastro Único Para Programas Sociais, até os mais complexos, como a requisição do Benefício de Prestação Continuada (BPC), casos de guarda e outros. As dificuldades resultantes da falta de informação e acesso às instituições fazem parte do cotidiano da maioria da população que participou das ocupações de São Gonçalo e Niterói. Foi a partir desta demanda que a equipe do Serviço Social construiu oficinas para os mais variados tipos de acesso a direitos.

Os plantões sociais no território, assim como a participação nas assembleias mensais foram essenciais para estreitar os laços com o movimento, fortalecer vínculos com os usuários e também para a formação dos discentes envolvidos no projeto. A experiência com o trabalho de campo em São Gonçalo, também foi utilizada como modelo para o trabalho realizado no ano de 2016 em Niterói.

Uma das ações centrais do trabalho no território foi a realização de um levantamento sobre todas as instituições públicas de mediação de direitos nos municípios que poderiam atender aos trabalhadores das ocupações. Essa ação reverberou em visitas de articulação e para levantamento dos serviços prestados no Ministério Público, Centro de Referência da Assistência Social (CRAS), no Conselho Tutelar, escolas públicas, locais de retirada gratuita de documentos, postos de saúde e unidades de pronto atendimento, escritórios modelo de direito da Universidade, Serviço de Psicologia Aplicada das Universidades, permitindo a elaboração de um catálogo institucional com serviços.

\section{- Instrumentos utilizados}

Segundo Guerra (2000), a instrumentalidade está inteiramente ligada aos complexos sociais, na contradição, na historicidade e na totalidade. O processo de mediação executado pelo assistente social deve ser feito baseado na realidade concreta, utilizando instrumentais que dão significado às dimensões da profissão, fazendo uso da teoria crítico social.

No processo de acompanhamento das famílias, destacamos alguns instrumentos básicos do Serviço Social como: observação, entrevista, trabalho com grupos, reuniões, mobilização de comunidade, visita domiciliar, visita institucional, além da sistematização da prática do trabalho que possibilitou processos de reflexão e formação para a própria equipe.

Além dos instrumentos utilizados para atendimento e acompanhamento das famílias acampadas. Iniciamos o trabalho, conforme mencionado acima, com a aplicação de um questionário estruturado para coletar dados quantitativos e 
qualitativos sobre o perfil da população, caracterização dos domicílios e acesso a direitos na região de moradia. O questionário elaborado, foi dividido nos seguintes eixos: sexo, raça/etnia/cor, estado civil, renda, trabalho, condições de moradia, acesso à saúde, assistência social, educação e serviços. O NEPFE teve a possibilidade de apresentar o resultado desta pesquisa para os moradores das ocupações de São Gonçalo e Niterói no 10 Encontro Estadual de Acampamentos do MTST no Rio de Janeiro, com isso, buscamos contribuir para o desenvolvimento de uma consciência coletiva crítica acerca das situações de violações de direitos que perpassam o cotidiano da população organizada pelo MTST. Os dados também foram divulgados na edição especial do informativo "O Formigueiro", elaborado, desde o período da ocupação pelos integrantes do movimento.

\section{Reescrevendo a palavra (e o mundo): aprendizados para a formação profissional}

Entendemos que os sujeitos coletivos se constituem enquanto organismos vivos presentes na sociedade e que as lutas sociais, políticas, econômicas e culturais podem e devem ser pautadas na produção de ações que proporcionem a essas coletividades a elaboração de uma identidade coletiva com perspectiva de classe e racial. A experiência com o trabalho nas ocupações do MTST possibilitou o levantamento de questões centrais: [i] a dimensão racial está intrinsecamente vinculada à classe social entre os trabalhadores ligados ao movimento, já que mais de $80 \%$ desses se autodeclaram como pretos ou pardos [ii] mesmo entre os pobres, os pretos e pardos apresentam piores condições de vida e moradia; [iii] a pobreza da população negra é espacializada, concentrando-se em lugares específicos da cidade e tendo na falta/inadequação da habitação sua maior expressão; [iv] os programas habitacionais no Brasil não dão conta de reduzir significativamente o déficit habitacional, essencialmente entre os mais pobres e majoritariamente negros; [v] a falta de alternativa via política pública estatal, principalmente, faz com que esta população se organize junto aos movimentos sociais na luta por moradia e demais direitos sociais.

$\mathrm{Na}$ atual conjuntura, extremamente desfavorável aos trabalhadores e de criminalização de sua resistência (e existência), é essencialmente importante o Serviço Social potencializar propostas de fortalecimento dos movimentos sociais baseadas na perspectiva contra-hegemônica ao capital com o objetivo de contribuir para um desenvolvimento político e melhores condições de vida para a classe trabalhadora. Nesse sentido, o projeto de extensão viabilizou a possibilidade de assistentes sociais e estudantes, apoiar e participar da ação dos movimentos sociais populares organizados vinculados à luta pela consolidação e ampliação da democracia e dos direitos de cidadania, como prevê o Projeto ético-político Profissional.

Assim avaliamos que projeto extensionista cumpriu um papel importante tanto para a construção e troca de saberes entre a Universidade e a sociedade, na relação estabelecida com o MTST, moradores e os docentes e discentes, assim como 
para reiterar a função social da Universidade pública. Um dos principais desafios colocados a esta experiência diz respeito a esse lugar lateralizado da extensão na Universidade. Os discentes envolvidos eram bolsistas de assistência estudantil ou voluntários. Para as atividades em campo, os professores utilizavam seus carros particulares, arcavam com os custos das impressões assim como os demais materiais da modalidade de extensão para uma discente da graduação em serviço social. Além disso, as primeiras oficinas ocorreram a céu aberto, pois neste período o movimento estava sem uma sede definida. Nessa experiência, assim como Paulo Freire "embaixo de uma mangueira", a equipe realizou inúmeras oficinas e reuniões embaixo de uma frondosa árvore, na certeza que mais que o espaço ideal a tarefa do Serviço Social era desenvolver a relação com os trabalhadores e conquistar sua confiança.

Os outros desafios se devem à conjuntura na qual este projeto foi desenvolvido, de cortes em direitos sociais e políticas públicas que o atingiram diretamente. Com o fim da modalidade Entidades do Programa Minha Casa Minha Vida e a não construção das unidades habitacionais, conforme havia sido acordado, o vínculo do Serviço Social com os usuários e a própria mobilização do MTST foi prejudicada, pois houve uma dispersão dos ex-acampados. Desde então, o movimento tem enfrentado muitas dificuldades em progredir na mobilização e organização para além da conquista das moradias, embora atualmente tenha reorganizado suas ações no território mediante o desenvolvimento do projeto "Cozinha Sem medo".

Experiências como a extensão realizada junto ao Movimento dos Trabalhadores Sem-Teto, constituem, assim, estratégias de fundamental importância para o fortalecimento do projeto profissional, bem como para que o Serviço Social possa construir caminhos de uma intervenção profissional que estabeleça resistência à atual conjuntura social, econômica e política. A extensão com o MTST aproximou os estudantes da vivência e das lutas de um movimento social, assim como dos debates sobre questão urbana e direito à cidade. Mas também evidenciou a distância entre a profissão e o debate da educação popular, o que nos impõe nos debruçarmos com mais envergadura sobre esta questão. Além dessas ponderações, a experiência também revelou um impulsionamento sobre a dimensão técnico-operativa, na medida em que, elegemos e construímos coletivamente os instrumentos do trabalho. Tal experiência potencializou o debate da instrumentalidade, se contrapondo aos reclames de uso frequente de que "a teoria não tem nada a ver com a prática", ou "na prática a teoria é outra". Nessa experiência, a prática revelou as análises da teoria, rompendo com a dicotomia entre teoria e prática.

\section{Referências}

ANTUNES, Ricardo. O privilégio da Servidão- o novo proletariado de serviços na era digital. São Paulo: Editora Boitempo, 2018.

BRASIL. Pesquisa IBGE 2017, 2019 e 2020.

CHIZZOTTI, Antonio. Pesquisa em Ciências Humanas e Sociais. São Paulo: Editora Cortez, 2008. 
FACEIRA, Lobelia da Silva. O Processo de Formação Profissional em Serviço Social e a Extensão Universitária: Avanços e Desafios. In: Revista da Pró-Reitoria da Extensão e Cultura - PROEXC. v.1, n.1, p. 44 - 98, Rio de Janeiro, jun. 2013.

Fórum de Pró-Reitores de Extensão das Universidades Públicas Brasileiras e SESu/MEC. Plano Nacional de Extensão Universitária. Edição Atualizada. 2000, 2001.

GUERRA, Y. A instrumentalidade no trabalho do assistente social. In: Cadernos do

Programa de Capacitação Continuada para Assistentes Sociais: Capacitação em Serviço Social e Política Social, Módulo 4: O trabalho do assistente social e as políticas sociais, CFESS/ABEPSS- UNB, Brasília, 2000.

GUERRA, Y. O conhecimento crítico na reconstrução das demandas profissionais contemporâneas. In: BAPTISTA, M. V.; BATTINI, O. (Orgs.). A prática profissional do Assistente Social: teoria, ação, construção do conhecimento. v 1. São Paulo: Veras Editora, 2009, p. 79-106.

LUKÁCS, Georg. Rosa Luxemburgo como marxista. In: História e consciência de classe, [1921]. São Paulo: Martins Fontes, 2003.

MBEMBE, Achille. Necropolítica, 1. ed, 2018.

MINAYO, Cecília de Souza. Pesquisa Social: teoria, método e criatividade. Petrópolis: Vozes, 2005.

MOARES, Camila Barros. Ressuscita São Gonçalo: a luta por moradia na ocupação Zumbi dos Palmares do Movimento dos Trabalhadores Sem Teto. 2016. Dissertação (Mestrado) - UFF, Rio de Janeiro, 2016.

NETTO, J. P. A construção do projeto ético-político do Serviço Social frente à crise contemporânea. In: CFESS/ABEPSS; CEAD/UnB (Org.). Crise contemporânea, questão social e Serviço Social. Capacitação em Serviço Social e política social. Brasília: CEAD/UnB, 1999.

SANTOS, Milton. O dinheiro e o território. In: SANTOS, Milton; BECKER. Bertha. Território, territórios. Ensaios sobre ordenamento territorial. Rio de Janeiro: Lamparina, 2007.

SILVA, Jailson de Souza e BARBOSA, Jorge Luiz. Favela- alegria e dor na cidade. Rio de Janeiro: Editora Senac Rio, X Brasil, 2005.

SILVEIRA, Maria Lídia Souza da. Educação popular: novas traduções para um outro tempo histórico. In: Seminário de Educação Popular. Rio de Janeiro: Centro de Filosofia e Ciências Humanas/UFRJ. CD-ROM, 2004. 


\title{
MULHERES DA ARTICULAÇÃO DE AGROECOLOGIA SERRA MAR: PRÁTICAS DE EDUCAÇÃO POPULAR FORTALECENDO AÇÕES EM REDE*
}

Suenya Santos

Vanessa Schottz

\section{Introdução}

\begin{abstract}
Radicalizamos nossa luta! Contra o patriarcado, o racismo, lesbofobia, contra qualquer imposição sobre nossa forma de amar, contra o capital: estamos em fúria feminista! (Síntese da Plenária das Mulheres no IV ENA - 2018).
\end{abstract}

O presente capítulo tem como objetivo compartilhar a experiência recente de organização do Grupo de Trabalho de Mulheres da Articulação de Agroecologia Serra Mar (GT Mulheres da AASM). Essa caminhada vem sendo construída coletivamente em interação com projetos de extensão popular desenvolvidos em universidades públicas numa perspectiva interdisciplinar e interinstitucional.

O GT Mulheres da AASM está inserido em uma estratégia mais ampla de auto-organização nos diversos espaços e redes regionais/estaduais que constituem a Articulação Nacional de Agroecologia (ANA). Em sua ação política, o GT Mulheres da ANA, que reúne, atualmente, mais de 300 movimentos e organizações, busca fortalecer e valorizar as experiências agroecológicas das mulheres nos diferentes contextos socioambientais, promover espaços de formação e incidir sobre as políticas públicas a partir de uma perspectiva feminista "popular, antirracista e antiLGBT-fóbico" (GT Mulheres, 2018).

$O$ ingresso no século $X X I$ vem mostrando que há um conjunto de opressões que vem sendo renovado secularmente pela sociabilidade capitalista com a finalidade de acúmulo de lucros para pequenos grupos, famílias e corporações no mundo. Além da exploração de classe, temos a opressão étnico-racial e patriarcal. Dessa forma, compreende-se a necessidade de as mulheres terem um espaço próprio para trocas sobre suas condições de vida e para se articularem e se fortalecerem enquanto sujeitos políticos. Nós mulheres somos protagonistas em diversas esferas e dimensões da vida, mas estamos sendo objetificadas há muitos séculos por opressões patriarcais, que anulam nossos conhecimentos, saberes e práticas, que superexploram e ao mesmo tempo desvalorizam nosso trabalho e que impõem regras sociais que limitam nossos corpos e nossas possibilidades de emancipação. Essas desigualdades são ainda mais fortes entre determinados segmentos sociais e essa iniciativa vem sendo construída para fortalecer mulheres agricultoras.

Nesse contexto, em 2017 tem origem o GT Mulheres da AASM como um coletivo que se articula em torno da defesa da agroecologia, dos direitos das 